(thes:

Detrital zircon source evolution during the Devonian-Garboniferous

\title{
colllision in the
}

Northern Moroccan Variscides

\section{-Cristina Accorro (accotto@ugr.es)}

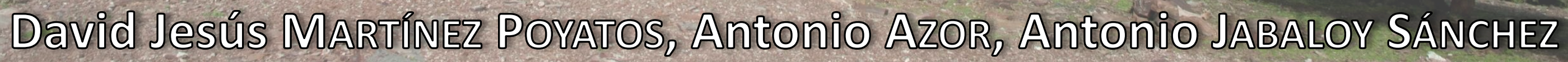




\section{OVERVIEW:}

- Geological setting: $\checkmark$ Moroccan Variscides

- Methodology and results: $\checkmark$ Geochronology on detrital zircon grains

- Discussion: provenance of the different detrital zircon populations and evolution of the sedimentary sources

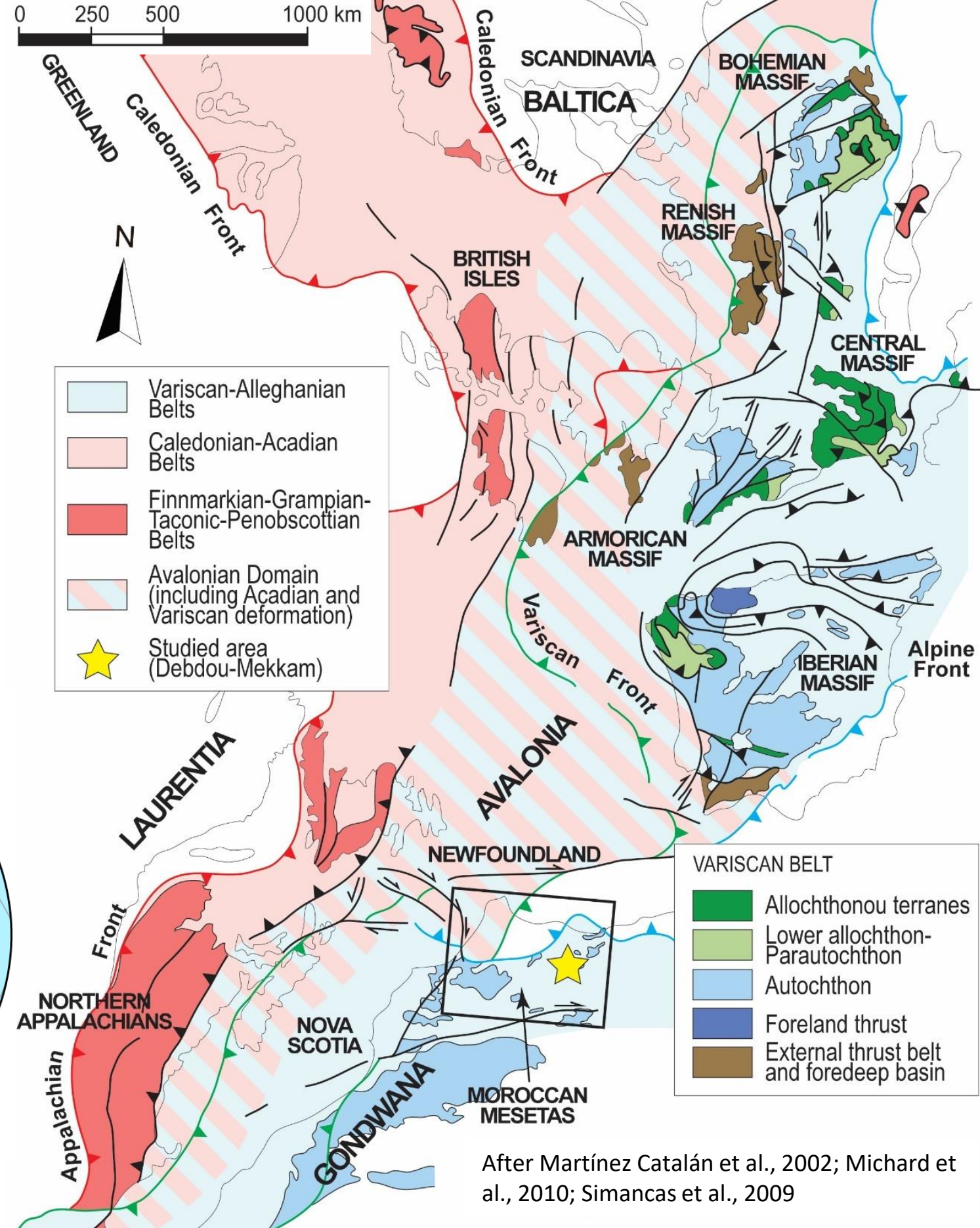




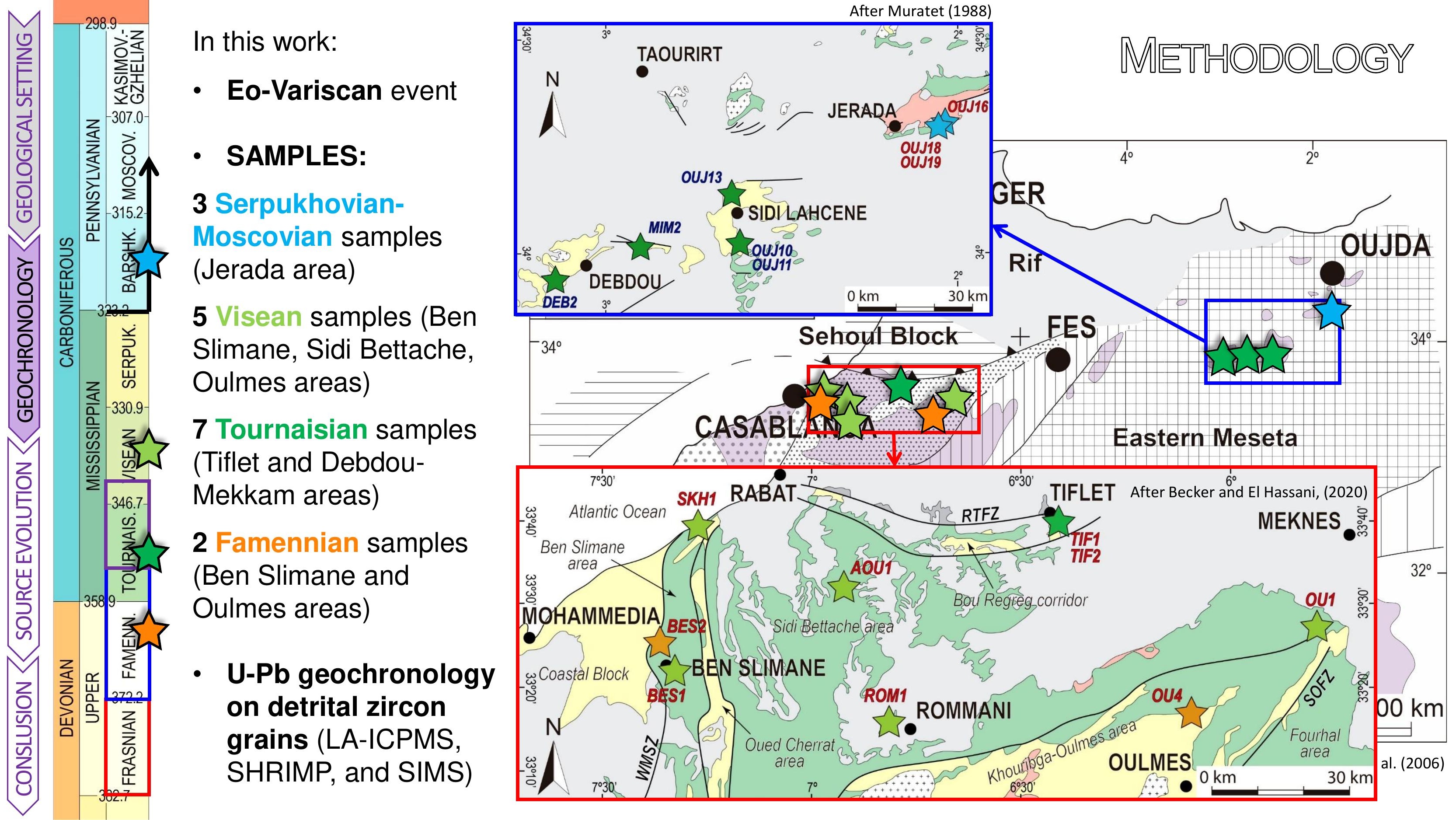



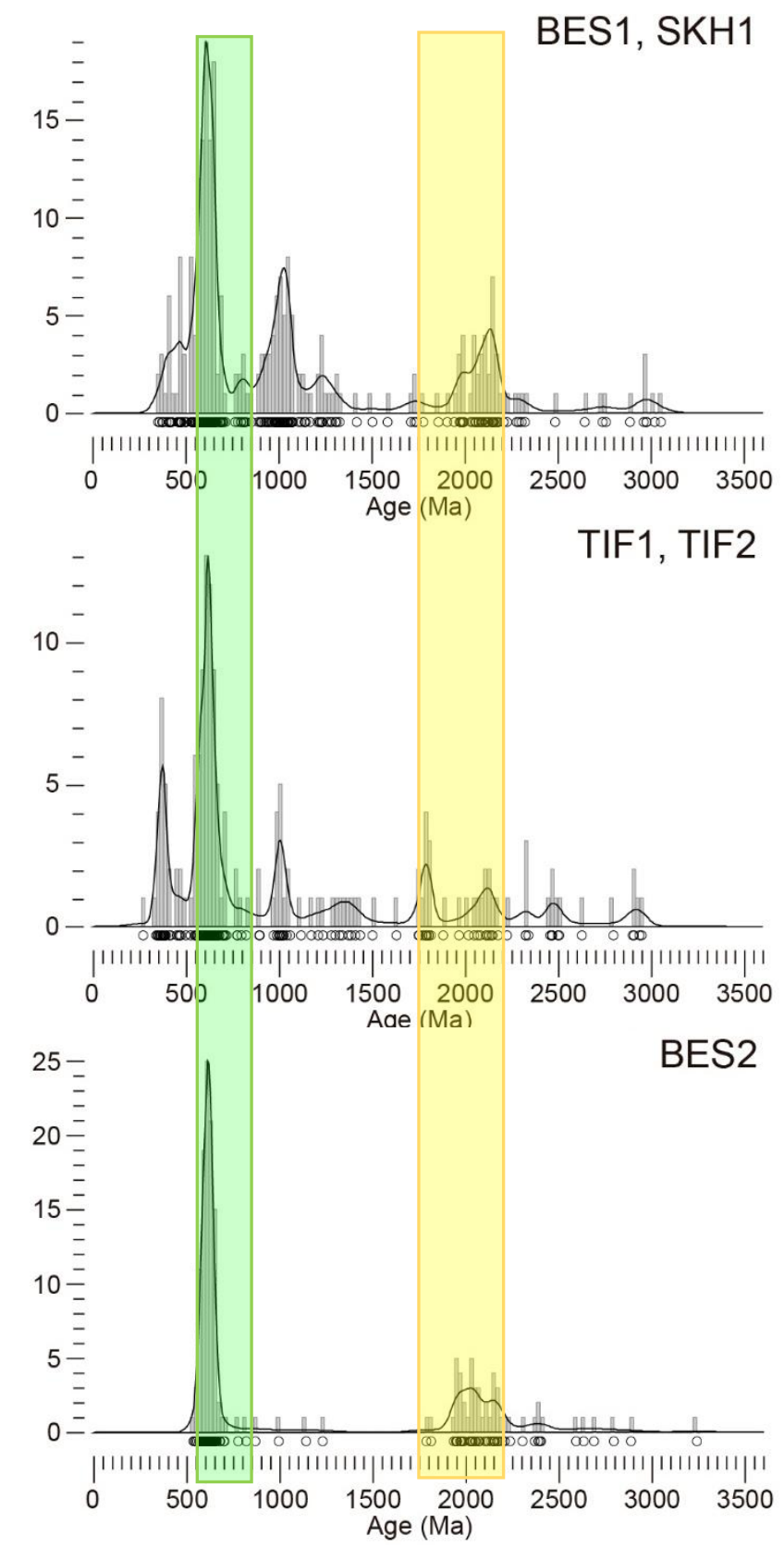

$(n=332)$
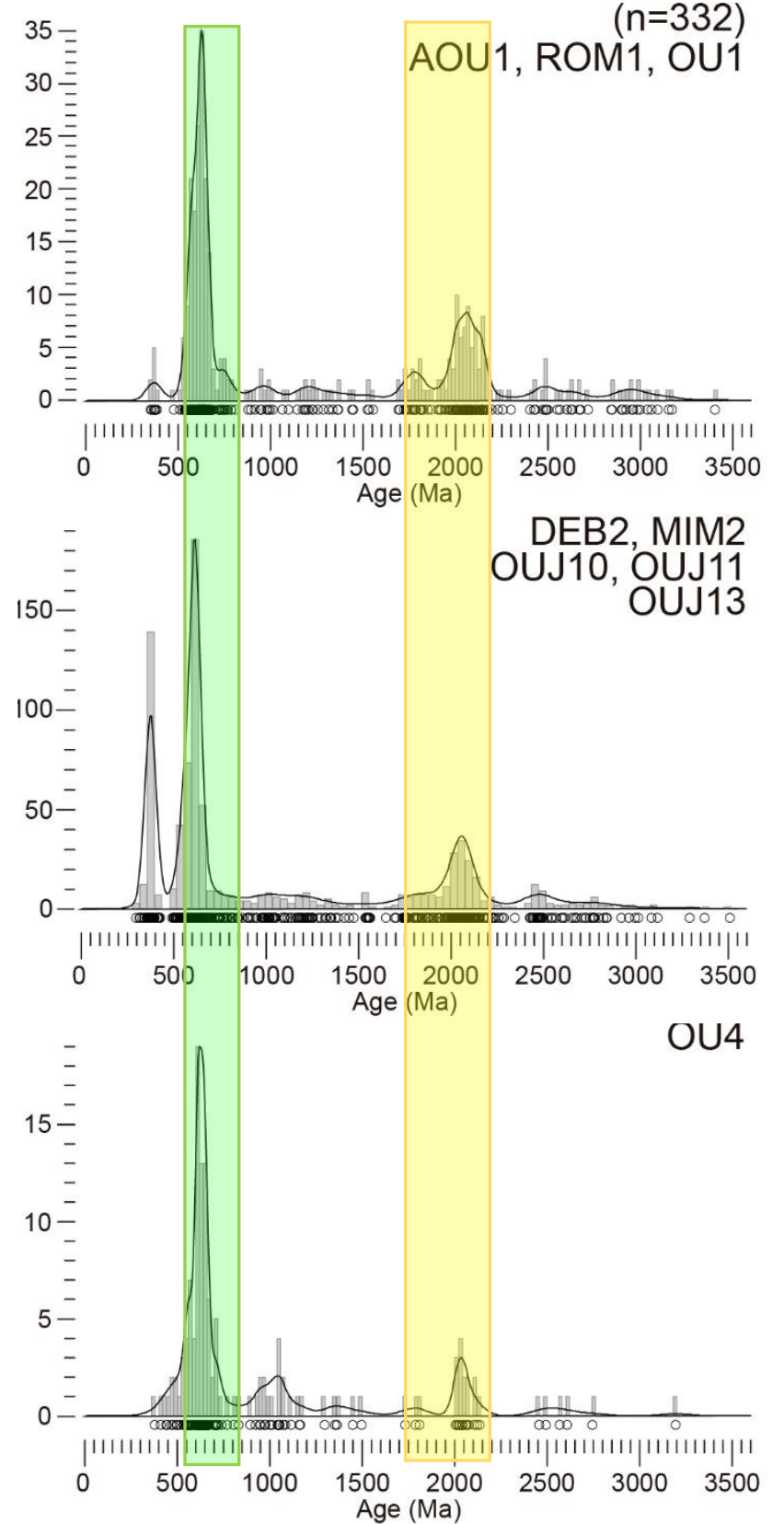

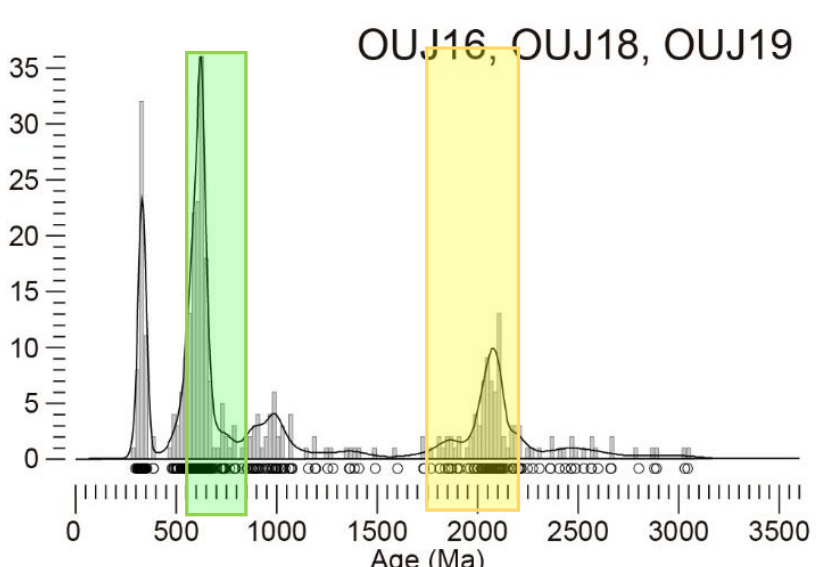

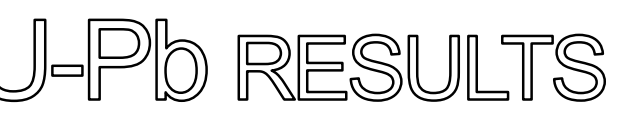

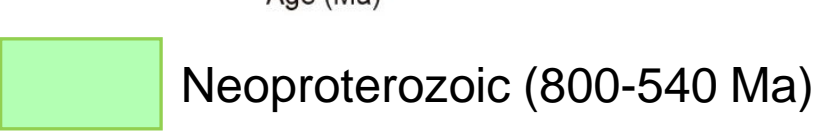

Paleoproterozoic (2200-1750 Ma)

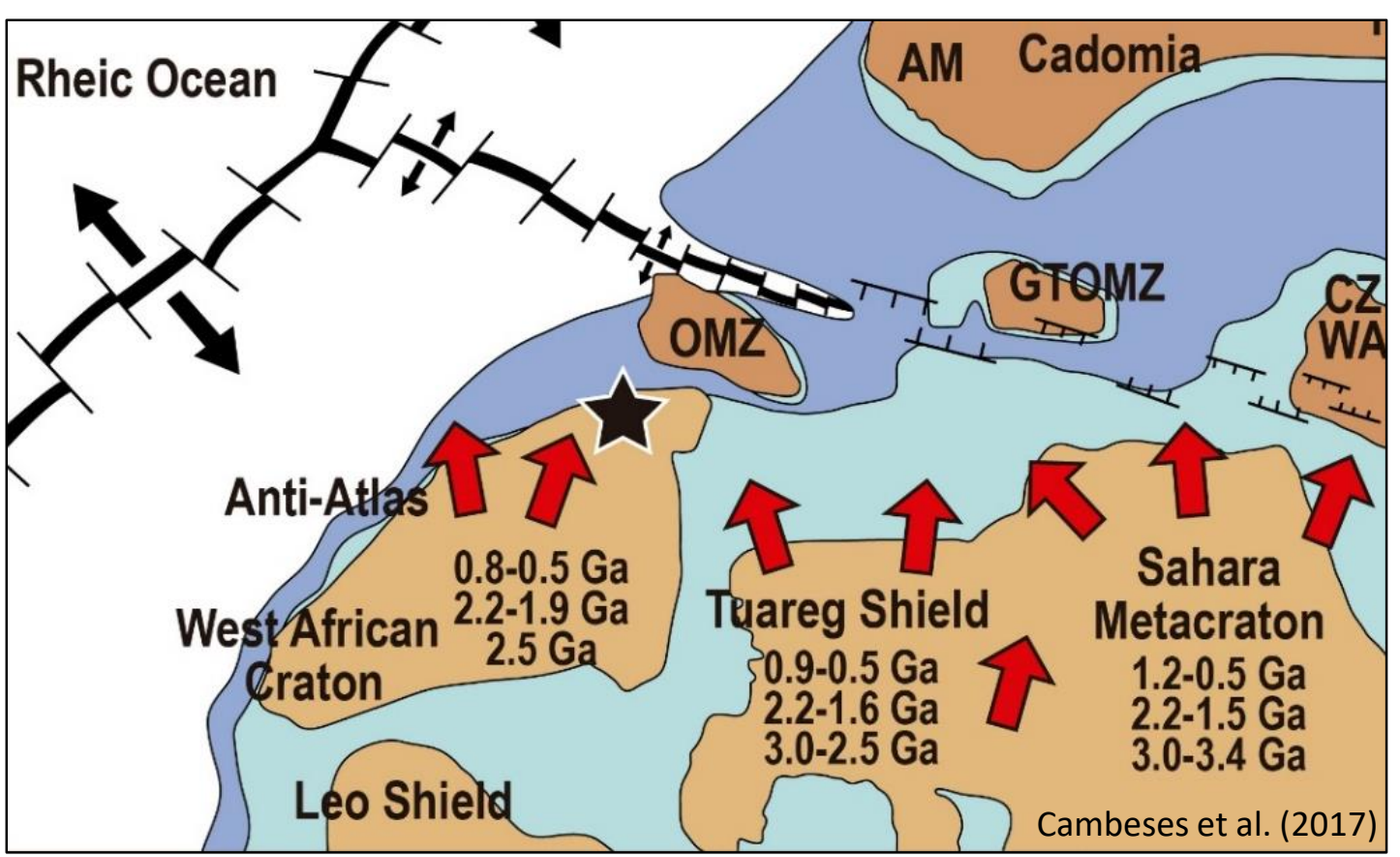



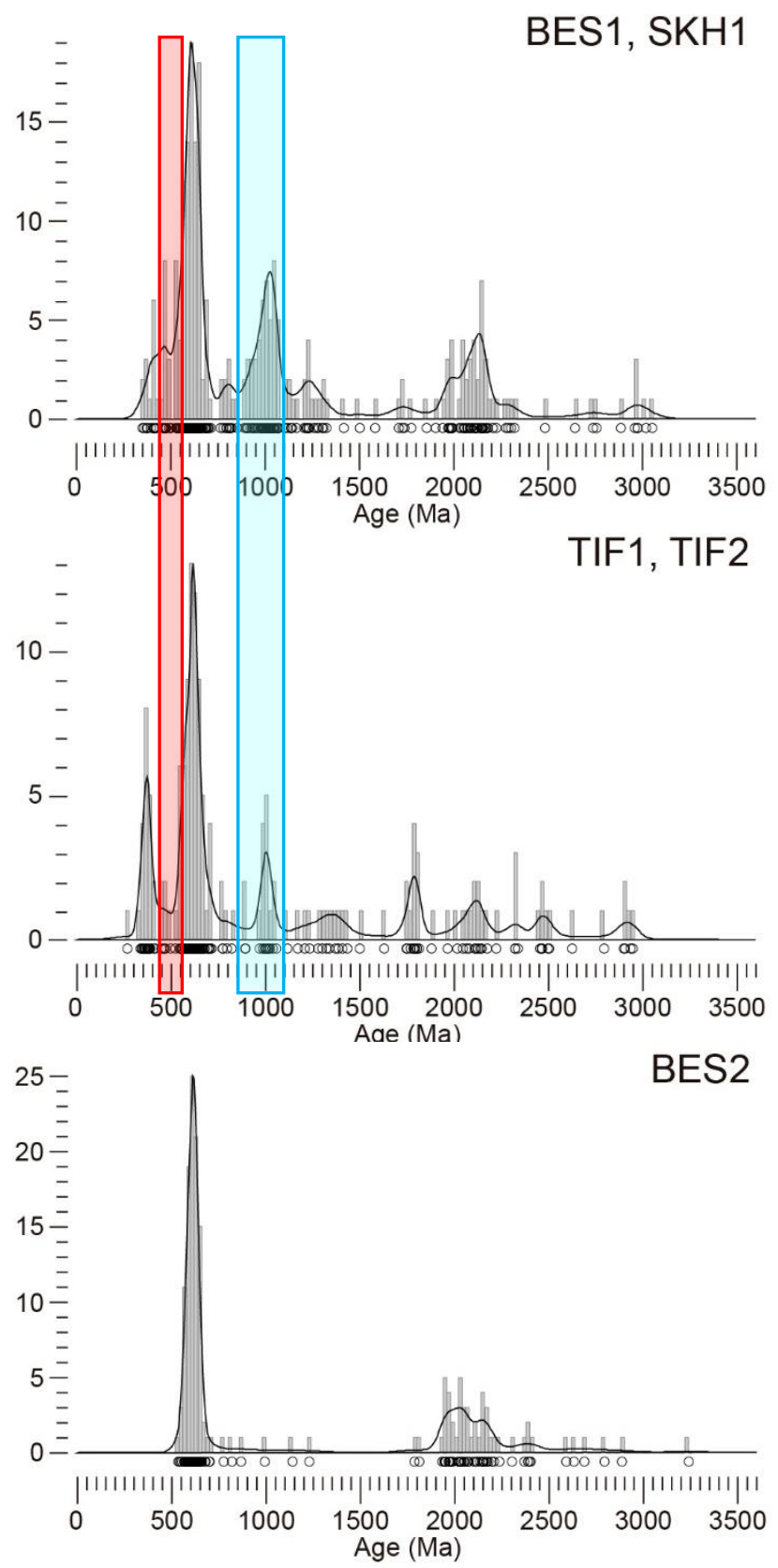

$(n=332)$
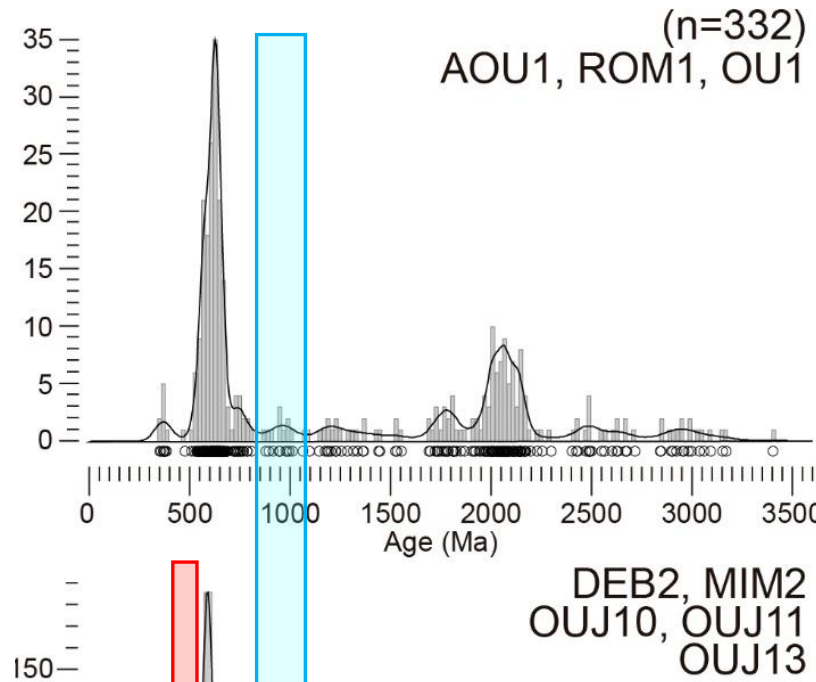

150
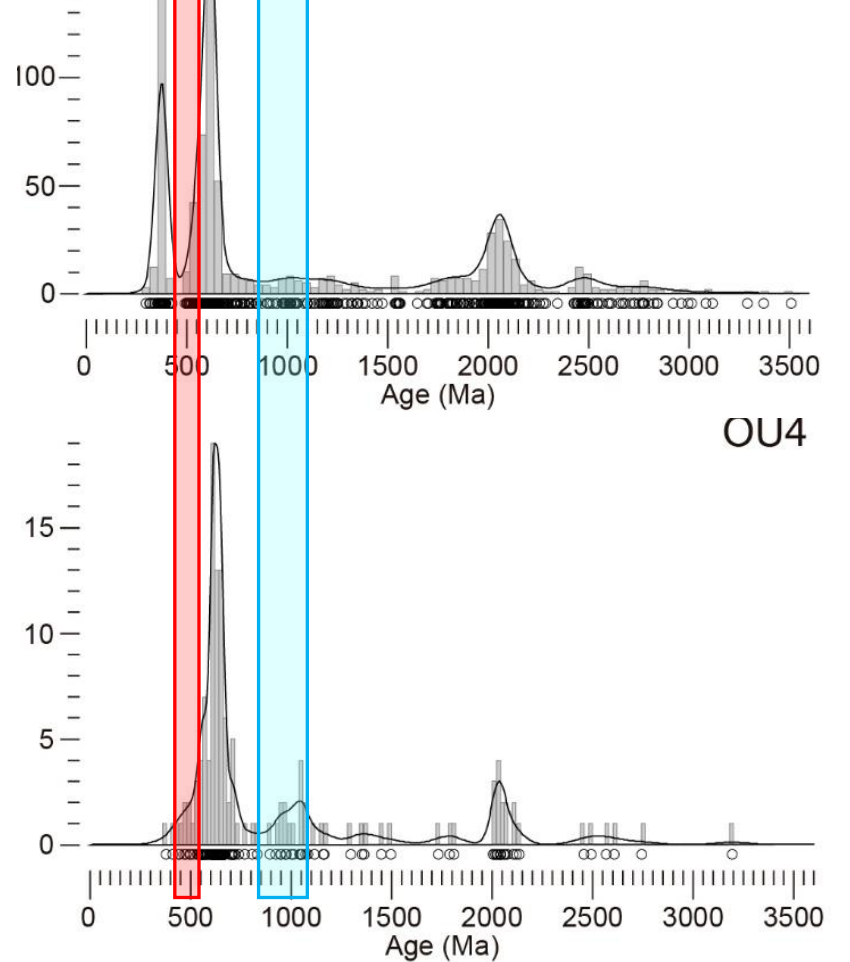

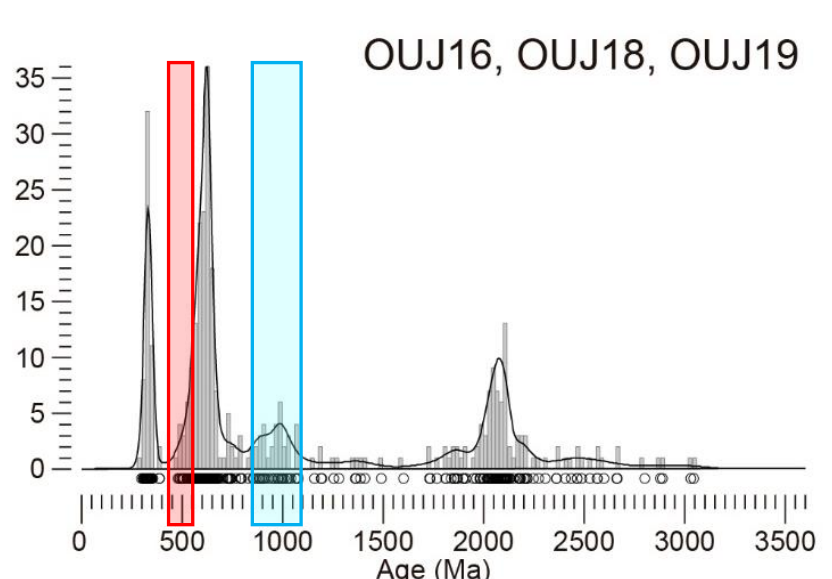

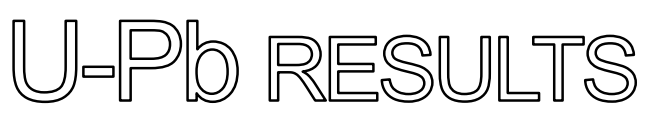

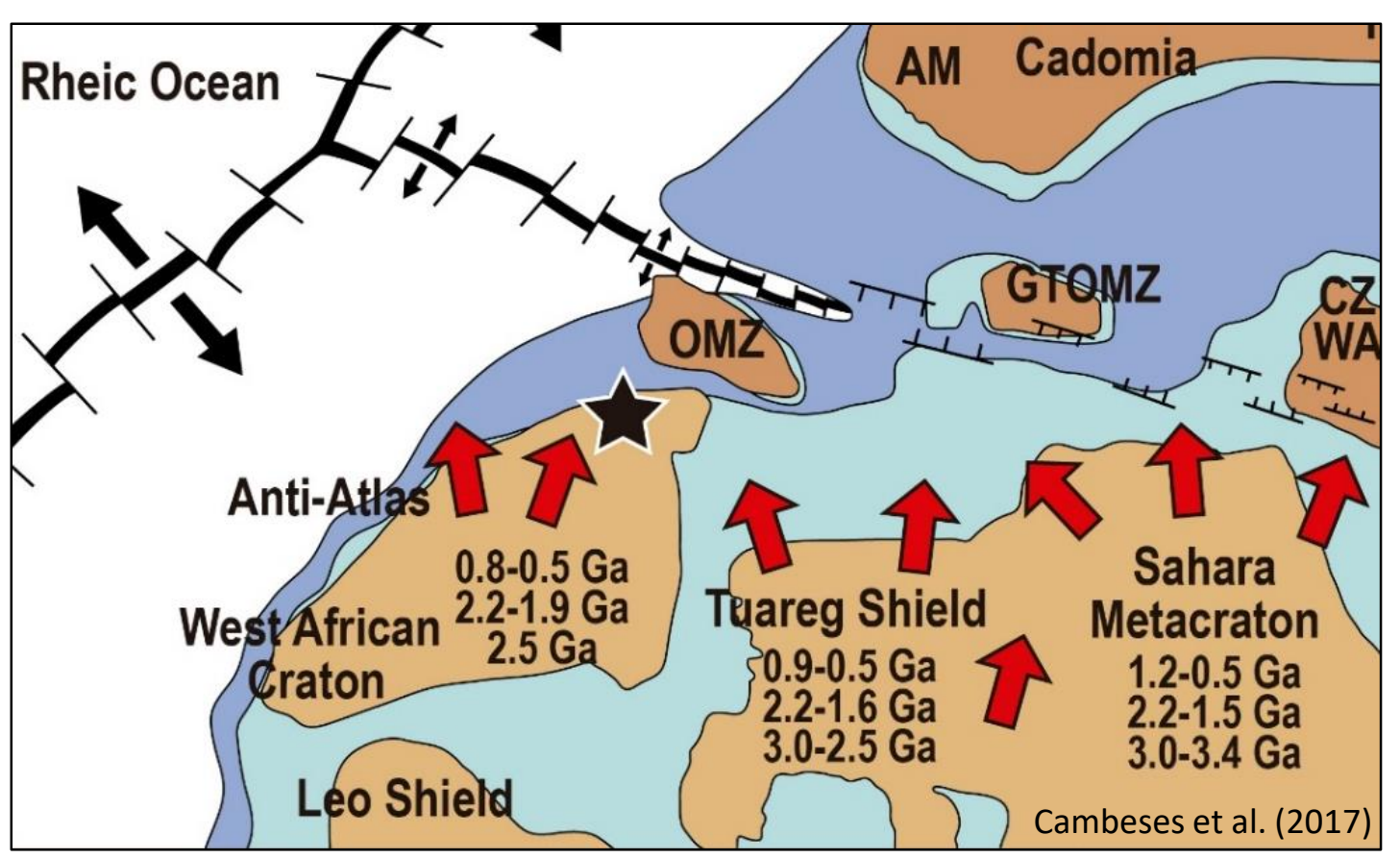



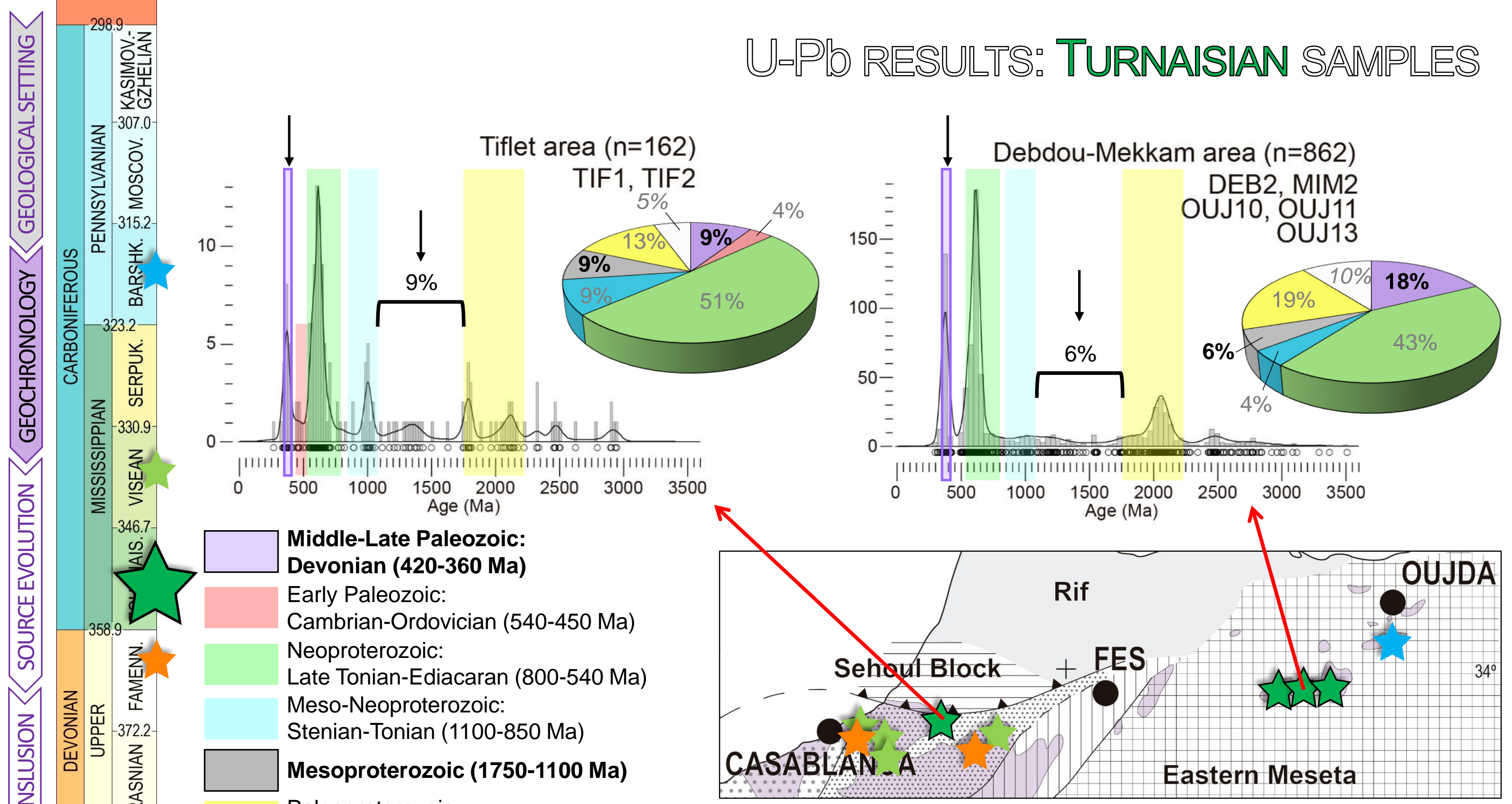

Mesoproterozoic (1750-1100 Ma)

Paleoproterozoic:

Rhyacian-Statherian (2200-1750 Ma) 


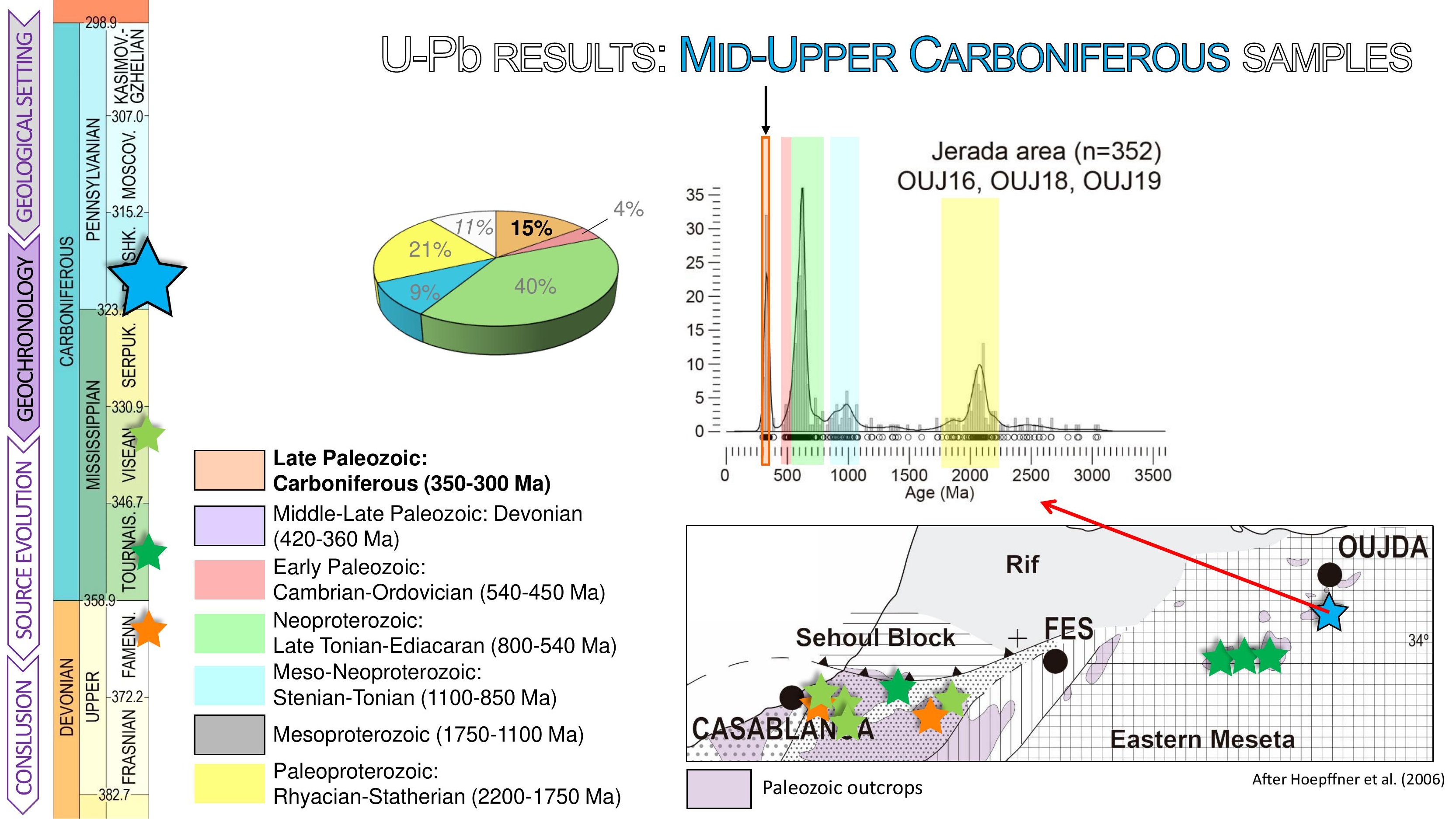




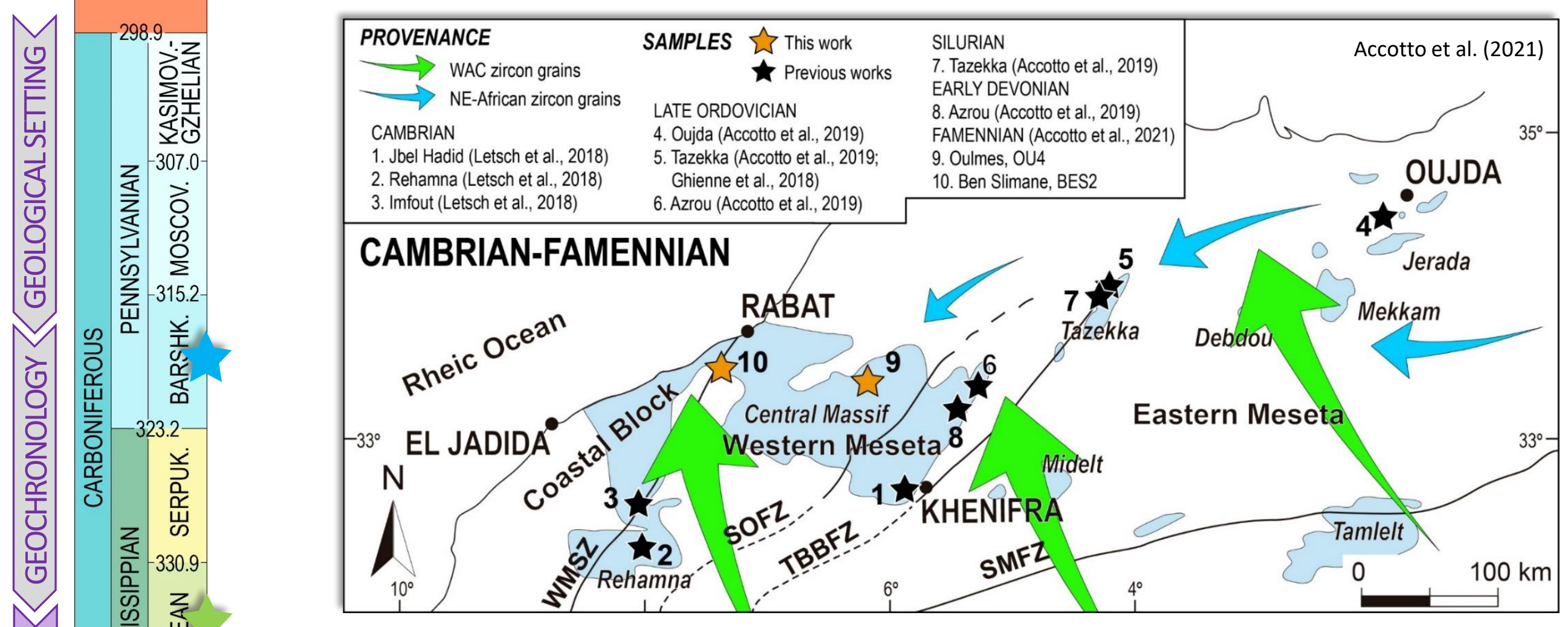

SOURCE

EVOLUTION

\section{LATE PRE-OROGENIC}
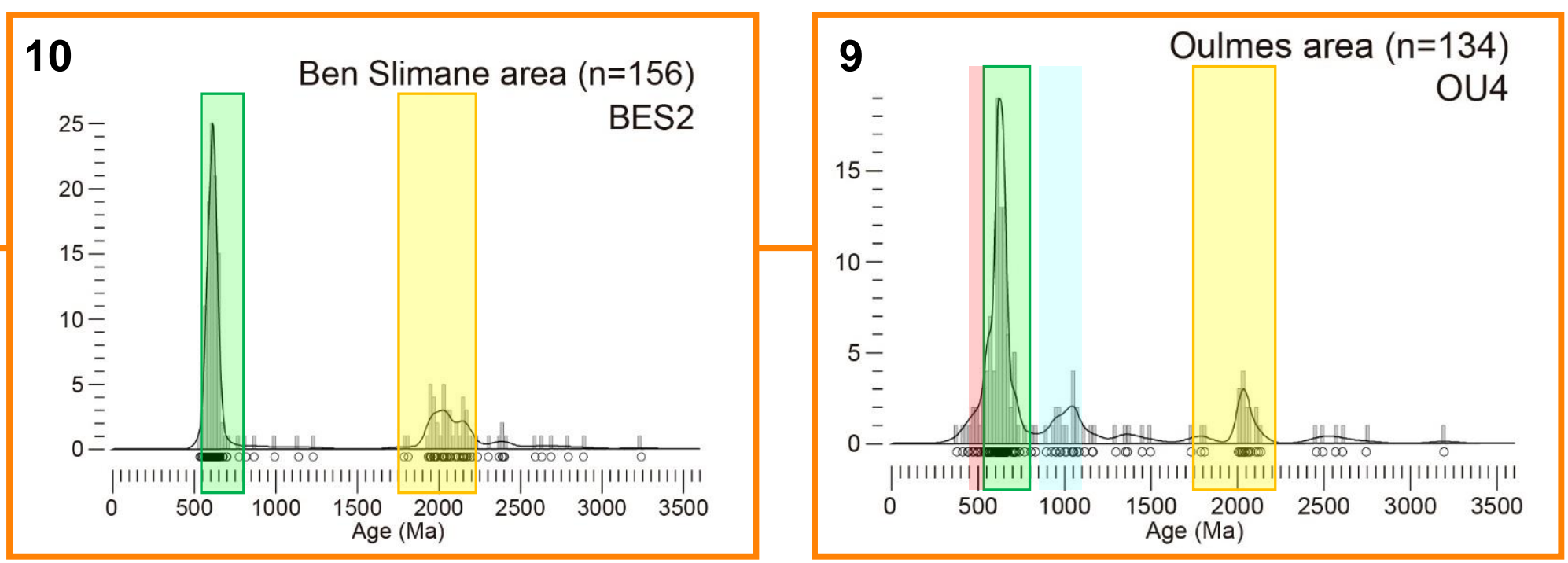


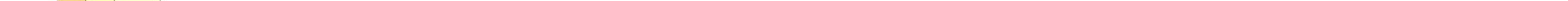




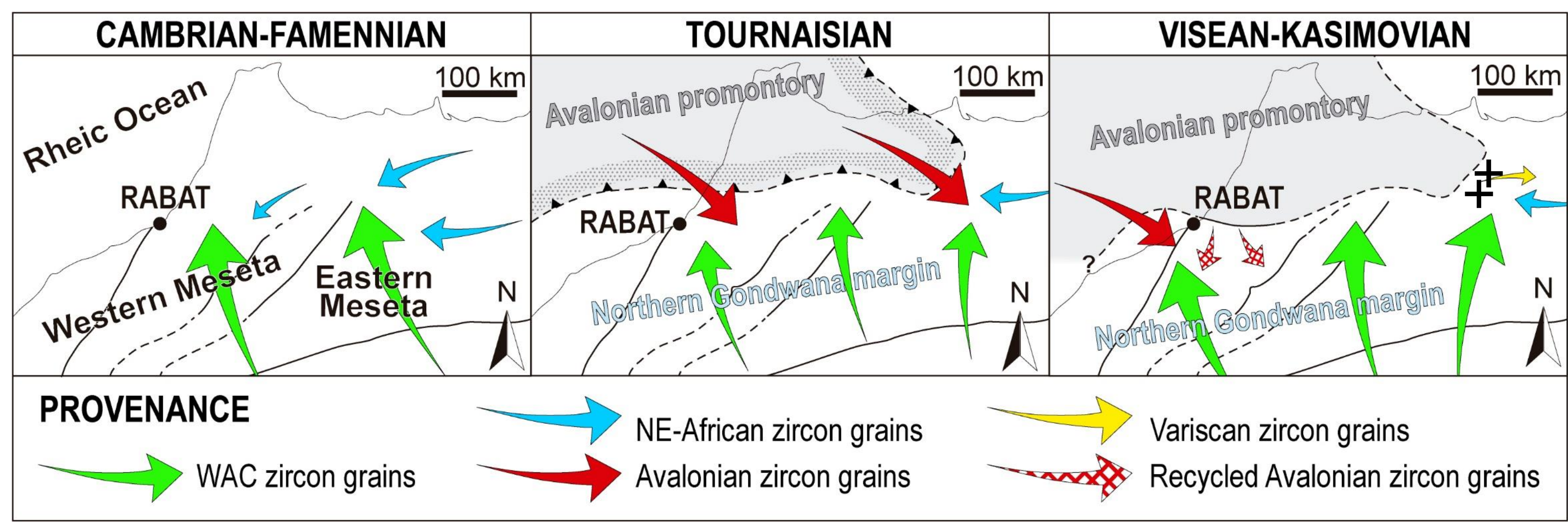

\section{PRE-OROGENIC}

- West African Craton

- NE African sources

\section{SYN-OROGENIC}

- West African Craton

- NE African sources

- Avalonian sources

\section{POST-OROGENIC}

- West African Craton

- NE African sources

- Avalonian sources (primary and recycled)

- Variscan granitoids 


\section{TIRANRK YOU FOR YOUR AATIENTLON}

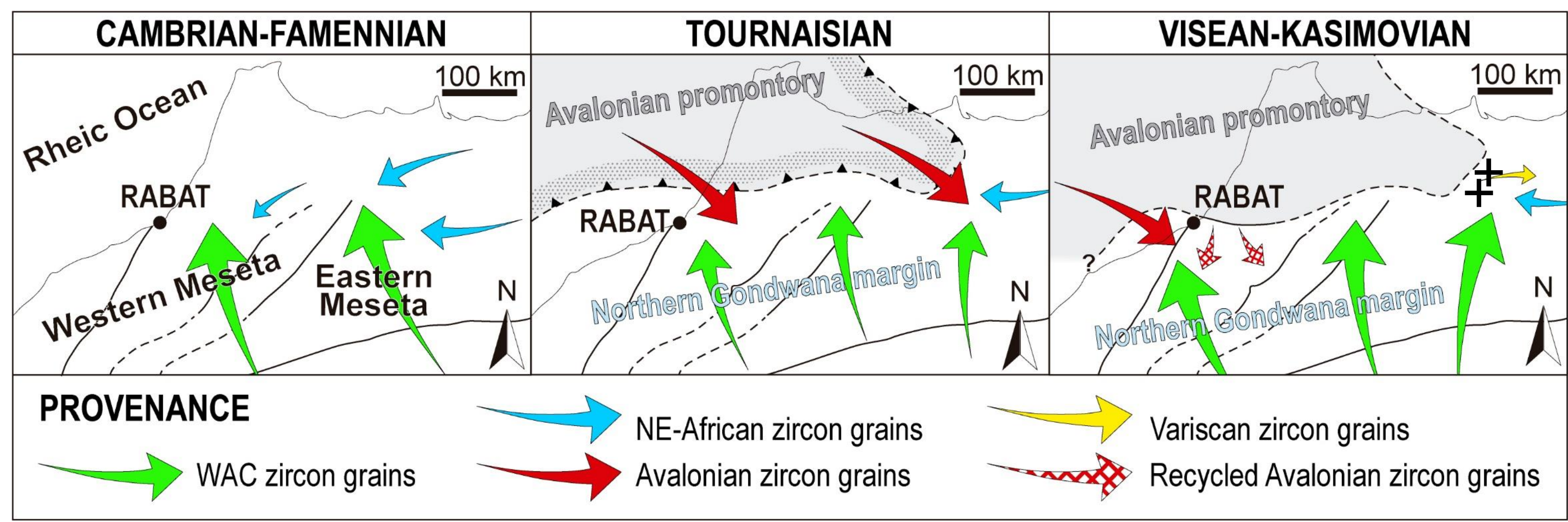

ACKNOWLEDGEMENTS:

- Cristina Talavera (University of Edinburgh, UK), Noreen Evans and Brad McDonald (Curtin University, Australia) for the LA-ICPMS, SHRIMP, and SIMS analyses on detrital zircons FUNDING:

- Doctoral scholarship BES-2016-078168 (Ministerio de Economía y Competitividad de España)

- Project PANGEATOR, CGL2015-71692 (Ministerio de Economía y Competitividad de España)

- Australian Geophysical Observing System grant 